\title{
Personal Development Empowerment through ICT in Corporate Learning: A Case Study of Two Developing Cities in China
}

\author{
doi:10.3991/ijac.v3i2.1280 \\ S. Lam ${ }^{1}$ and Ho Kin Fai ${ }^{2}$ \\ ${ }^{1}$ Oxford University, Oxford, UK \\ ${ }^{2}$ Hong Kong Polytechnic University, Hong Kong
}

\begin{abstract}
Human development despite faltering economic development has been taking place in China where is one of the fastest growing countries in the world. While the formal government sector continues to play an important role, it is the growth of private participation in providing suitable ICT training, especially to the socially and economically under-privileged that appear to have provided the impetus for growth in qualified professionals. This paper argues that the use of ICT in corporate education and training is likely to empower their employees skill sets. The results of this study, which apply two Chinese cities as a case analysis representing the use of ICT could be an effective teaching tool for multi-national corporate learning in developing cities. The authors also have developed a 4Is framework for discussion.
\end{abstract}

Index Terms-ICT, Empowerment, China, Corporate Training

\section{INTRODUCTION}

It is widely recognized that one of the vital determinants of competitiveness in developing countries is the skills of the workforce at all levels. The effective use of technologies requires skills, and the move from simple to complex technologies requires more, better and more diverse skills. Further, new technologies often call for entirely different skills, both for direct production and services and for the organization of production and for managing knowledge networks. For example, as the momentum surrounding e-commerce increases with more and more people turning to World Wide Web to conduct business transactions, the demand for Web professionals is reaching a feverish pitch. The need for increased skills rises with the level of development, but even the least developed countries have to improve their human capital base if they are to grow and prosper. Traditional models of competition based on low costs and prices are being replaced by competition driven by quality, flexibility, design, reliability and networking. This change is not only in markets for advanced manufacturers but also in day-today use consumer goods like clothing, footwear and food products.

The use of new technologies, especially information based technologies, calls for more, better and newer kinds of skills. The reason for this stems largely from both technological factors, as well as organizational factors. These skills are subject to constant change. Consequently, the education and training system in corporate learning has to upgrade skills constantly in line with emerging needs. International Labour Organisation (ILO) [1] observed that the demand for professionals and technicians has increased in all countries, as their analytical, cognitive and behavioural skills equip them better to adapt to more sophisticated technology. In addition, the increased importance of networking between firms [and between firms and technology institutions] for competitiveness, requires specific "communicative" skills. A recent study [2] shows how these skills are enabling skilled workers in the UK to move into knowledge-intensive sectors more readily than worker without such skills. Skilled and experienced individuals can provide an economy with greater technological capabilities for fostering growth in output and social welfare [3].

In a world of fast changing technology, however, a base of formal education is necessary but nor sufficient for efficiently using technologies. Technology-specific skills and learning are as much important as the formal education is. Better capabilities, especially in microelectronic applications and use of information technology, for job seeking is expected to bring about a change in the socioeconomic structure of the society. This is especially when such skill formation efforts, in developing countries, are directed to socially and economically underprivileged.

Moreover, as the industrial sector grows more complex and sophisticated, the challenge of providing better and more appropriate human capital becomes more important. In the process, therefore, relevant institutions develop. However, given the complexity of the information involved, the long-term nature of skill investment and the inherent uncertainties and externalities, there can be widespread market failures in human capital formation. As a result, markets can fail to provide properly an economy's skill needs and to keep with its changing profile. There is a clear need for policy support from both public and private sectors. The authors would like to conclude that a career long approach requires the transformation of processes and policies that support learners, their education, their work and their growth in the profession. The use of ICT training has the potential to support such policy goals especially in remote places. But how can the use of ICT support goals of social justice in corporate learning in developing countries like China? What kind of arrangement should we use in achieving the goal? 


\section{A. The importance of research}

Many evaluations [4,5] of ICTs in developing countries rely on correlational designs to test whether variables are associated with each other and utilize a qualitative or case study approach. Such an approach provides a detailed look into why and how ICTs may be used within educational settings to boost learning outcomes, but not whether their usage leads to desired outcomes over time. Moreover, there exists an ongoing discussion on how to define and measure impact in this field, creating a substantial barrier to conducting rigorous research and developing comparable evaluation designs. Challenges also exist at the program implementation level. Competition for scarce funding often detracts from the importance of measuring impact for policymakers and practitioners.

This study is unique in its focus on studies conducted within two cities in China in a comparative approach to better understand benefits and challenges to implementation in those contexts. In this study, both qualitative and more rigorous experimental techniques are discussed. This study aims to analyze the impact of the use of ICT in corporate learning and hence on the Socio-Economic structure of the beneficiary. Specifically,

1. the study proposes to take up the case of ICT education programme of a particular corporate learning centre;

2. evaluate the challenges of ICT for corporate learning in developing city contexts; and

3. the study would compare the socio economic impact of this programme in select centres in two cities in China namely Tianjin and Kumming. Both cities are undergoing major development with many multinational companies setting up offices in the city.

\section{LITERATURE SURVEY}

Corporate learning is not uncommon in most developing cities as many multi-national companies have to maintain its service standard. As mentioned earlier, developed countries, with the most developed skill base, that appears to worry most about human capital formation. Developing cities have always been a path dependent on this. However, recent experiences of Asian tigers reveal that those countries / cities, which have built strong human capital, are the ones that are able to grow at a faster rate than the others. Studies on evaluation of poverty alleviation programmes have also pointed out that ICT could be a major route through which cities could expedite eradication of poverty. Computer education, which is an integral part of the information technology development, appears to have tremendous scope to enhance staffs' opportunities in less developed places by improving their access to other part of the world increasing its global exposure. It is particularly importance for multi-national companies.

The literature for this report is identified through several mechanisms, including web-based searches of educational and other special interest databases, a call for papers and recommendations resulting from in-depth qualitative interviews conducted with experts in the field including practitioners, developers and users of ICTs. Extant literature on the impacts of interventions employing ICTs can be divided into five groups: (1) empirical and qualitative research on ICT interventions in the US and other advanced economies [6,7]; (2) empirical and qualitative research on ICT interventions in developing countries; (3) theoretical reviews on the importance and utility of ICT in corporate learning [8]; (4) studies examining the cost effectiveness of ICT interventions [9,10,11]; and (5) policylevel reviews or "educational technology master plans, that provide a vision for the use of technology in education and institute programs that support this vision" $[12,13,14,15]$ conducted by Ministries of Education in developing countries. The focus of this article is solely on extant evaluations of ICTs on student learning outcomes within developing cities.

The real issue that emerges from these studies on developing cities is that efforts should be made to close the digital gap through incorporating ICT directly in development work - not just include ICT in other projects. The solution is to move from a very narrow ICT focus to a holistic view. In this broader view ICT is the link to other issues: Human capacity, policy, enterprise, content and infrastructure. The holistic view also makes it necessary to expand focus from macro-economic dynamics to include locally embedded approaches.

To sum up, it could be mentioned that on the whole the use of ICT appears to have tremendous scope to enhance corporate learning development in developing cities where is far away from its regional headquarter. These opportunities are usually translated in the form of access to learning materials and learning materials access could be a part of the development initiatives in a world of information technology and could make the development initiatives inclusive. In additional, trainers based in the headquarter are in a much better position to monitor the process. Provision of ICT education inn corporate training could, therefore, be a major source of empowerment of existing workers' skills - especially those belonging to the socially and economically backward in a developing country like China. The results of the analysis in this paper could be of considerable use to the foundation and the policy makers and also provide directions for future research.

\section{A. Computer Training}

Many corporate organizations especially in remote locations like to outsource their training to local specialists so that they can concentrate on their business. As a result, there are many local training centers within the city. This section describes the characteristics of the selected Computer Training Centres located in both cities - Tianjin and Kumming. There are 34 running centres in theses two cities put together: 17 each in Tianjin and Kumming. The project team visited all the 34 centres and collected data pertaining to the structure of these training centres, basic amenities, infrastructure facilities, location, number of PCs and the utilisation of the facilities. The region-wise as well as centre specific details are presented in this section.

\section{B. Centres in Tianjin}

This section provides a brief description of the structure and facilities available in the computer training centres in Tianjin. The assessment is carried out on the basis of factual information about the existence and functioning of computers, location of the centres, infrastructure index, dropouts, placements and capacities and their utilisation.

Four of these 17 centres have been in operation from the past five years. Two centres have 10 PCs each and the average number of PCs is about 5 and most of them are in good working condition. However there are a number of centres which do not have a female instructor. More than 
half the centres are located in market places in Tianjin, while a third of them being in residential areas. Except 2 centers, all others score $60 \%$ and above in infrastructure index. There is lot of scope for improvement on this front in most centres. In most centres, very low percentage of past students is in contact with the faculties.

Capacity utilisation has been one of the major concerns. It is evident that in only four out of the 17 centres register a capacity utilisation of $40 \%$ and above. Eleven out of 17 centres are at less than one third of their effective capacity. The ratio would be extremely low if calculated in terms of installed capacity.

\section{Centres in Kumming}

In contrast to Tianjin, Kumming has very few female instructors (only 4 in all). Also the total number of instructors in a centre in Kumming is not more than two.

A practice not followed in Tianjin. This puts a greater burden on the existing number of instructors especially when the number of PCs is 8 to 12 . Most centres in Kumming are located in residential areas, which provide easy accessibility. Less than a third is located in market areas. On the infrastructural facilities, nine out of seventeen centres score above $60 \%$.

As against poor utilisation of capacities in Tianjin, Kumming has a high rate of capacity utilisation in many centres. Only six out of 17 centres have less than one third capacity utilisation. High capacity utilisation could be due to a large gap between installed and effective capacity, which is mainly due to less number of instructors and number of working PCs.

To sum up, this section attempted to provide an analysis of computer training facilities available in the centres surveyed in both cities. The analysis highlights the scope for improving infrastructure facilities and better capacity utilisation. In addition, there is a need for increasing the number of female instructors.

\section{METHOD}

\section{A. Personal Development Assessment of the Beneficiaries}

\section{1) Qualitative interviews}

In preparation for this paper, the authors also contacted 40 experts in this field, including trainers, academicians, corporate human resources mangers and practitioners, working in both cities in China. Both users and developers of ICT solutions were contacted. Of these 40 individuals, 25 agreed to in-depth telephone interviews. This is a unique component not found in traditional desk studies. The goal of this effort was to request unpublished reports on the educational impacts of ICT in these two developing cities in China and to obtain a more detailed first-hand account of the challenges associated with developing, implementing and evaluating ICT interventions in these developing cities. Interview questions depended upon the expertise of the individual, but generally included:

- In your opinion what is the future of low-cost and other ICT devices in corporate learning in developing cities contexts?

- Is there a widespread need for these types of solutions?
- What changes should be made, if any, to the use and development of ICT in corporate learning?

- What, in your opinion, are the two or three most important considerations when planning and deploying ICT for corporate learning?

- What are the challenges to implementing these solutions in developing/emerging cities?

- (For users of ICT solutions) What resources are available and what do you still need? What are the challenges to using these types of devices? What solutions are you most excited about?

\section{RESUlts}

In the course of our survey we visited a total of 34 ICT training centres in both cities. In this section we present a personal development assessment of the beneficiaries of the two months' Diploma in Computer Application programme which is specially designed as part of the corporate training. The information pertaining to age, sex, educational qualification, occupational status and family, discussed here have been collected from the students' Enquiry cum Admission forms. Most centres preserves the forms very neatly although many forms are far from complete. The analysis carried out in this section is largely based on the assumption that the information provided by the beneficiaries in the form is true to the best of their knowledge.

To carry out the personal development assessment of the beneficiaries, we have looked into gender distribution of the total beneficiaries, age structure, gender distribution of age structure, educational level, and gender distribution of educational level, and income distribution. The total size of the sample is 5991, of which Tianjin and Kumming accounts for 3800 and 2191 sample observations respectively. The sample size has been determined by the number of forms which were available for observation, when we visited the centres, and did not reflect the actual number of beneficiaries of the all the centres put together. The share of females was found to be $30 \%$ for the whole sample, 34\% within Tianjin and 24\% within Kumming.

The age structure of the beneficiaries of the programme gives us an idea of the distribution of the beneficiaries according to their ages. It was observed that Tianjin performs better than Kumming in catering to the more productive age group. However Tianjin has the largest share in 30 to 60 years age group. From our results we find that nearly $75 \%$ of the beneficiaries of the training programme in Tianjin are in the age group of 15 to 25 years as against nearly $80 \%$ of the beneficiaries in Kumming. This may partly be explained by the fact that in Tianjin, the ICT course has been very popular among working persons especially those employed in the financial industry where is proposed to become the second largest financial center in North China after Shanghai.

As regards the gender distribution of age structure, it is seen that the share of males is higher than that of females. In Tianjin, in the Age group of 15 to 20 years, the share of females is $17.14 \%$, and in the 20 to 25 years' age group, the share of females is $10.4 \%$. In Kumming, only $10 \%$ of the beneficiaries are females in the age group of 25 to 30 years and its share rises slightly to a $15 \%$ in the age group of 30 to 60 years. Its unbalanced gender distribution is mainly due to the one child policy in China where the male birth rate is much higher. 
In the following account we assess the break-up of the beneficiaries according to their educational level. It is evident from our results that $64 \%$ of the beneficiaries are those who have completed junior school education. 30\% are graduates who have greater potential to get a job. While Kumming dominates in college graduate categories, Tianjin has a higher share among the post graduates. In China, many graduates with higher degree of education would prefer to go to east coast for job hunting as it is more developed with more opportunities especially in the tertiary industries.

An analysis of the gender distribution of the educational level in both Tianjin and Kumming, indicate that for most of the centres, across all levels of educational qualification, the share of males is much higher than that of females.

An idea of the income distribution of the whole sample taken together and our results shows that $40 \%$ of the total sampled beneficiaries come from families whose annual income is less than RMB30,000 (US\$3,500). Lower middle income group in the range of RMB.30,000 to RMB.60,000 (US\$7,000) represent 34\% of the beneficiaries. Together therefore, $74 \%$ of the people benefiting from the subsidized computer education training facility are from the low income group which do not pay any income tax. This indicates that special financial arrangement such transport assistance in order to encourage the under privileged group to participate the training. Another main concern is that most of the people in the low income group do not have a computer at home. It means that they cannot do their own practice at home. Despite progress in expanding the reach of basic and new ICT corporate learning in China, the majority of the population especially the low income group still does not have access to computers and the Internet. Moreover, there is a wide and uneven disparity along the fault lines of social inequality such as socioeconomic status, age, gender, geographic location and ethnicity.

From our survey finding, it is evident that Kumming has the largest share of beneficiaries from the poor income group (59.6\%) and from lower middle income group (30.2\%). Tianjin also has a large share (43.6\%) in lower middle income group, but relatively low share (17.9\%) for poor income group. The authors believe that company sponsorship is extremely importance in developing corporate training in these cities due to the financial constraints of the employees.

But whatever the company policy stance may be on workers' continuing professional development in corporate training, the mechanisms and resources for enabling workers' career-long learning commonly fall short of what they need to be. In some cases, local companies routinely need to spend over 90 per cent of their human resources funds on workers' salaries, leaving little spare funds for a number of competing demands including workers' professional development. In addition to these financial constraints, traditional conceptualizations and forms of in service education may be strongly entrenched, not just in institutional practice but also in the structure of budgetary allocations. This limits delivery options and can result in a norm of out-of-school, off-the job, infrequent or rare learning opportunities for a selected minority of workers at high per capita cost. In such a scenario, rural and geographically remote workers are frequently at a disadvan- tage and this contributes to the rural-urban educational quality gap observable in China.

\section{A. Challenges of the use of ICT in corporate learning in Developing Cities}

According to our in-depth interview, the authors would like to summarize the following mentioned problems for corporate learning in both developing cities:-

- Lack of appropriate products: products are often not designed to meet the needs of the local. These groups can face constraints such as access to ICT related products.

- Cost: roughly half the working population live on less than US\$10 a day. Many potential users are too poor to afford any form of access to ICT.

- Education: even where there is physical access to ICT, many people do not have the technical skills needed to benefit from them.

- Language: Poor literacy is a problem with ICT such as the internet. Of those who can read, many know only a local language, while the internet is dominated by English-language content.

- Human resources: As in many sectors, the migration of skilled ICT professionals from developing to developed countries contributes to a lack of human resources to support ICT.

- Absence of Standardized Evaluation Framework for Educational Interventions using ICTs: As discussed with trainers and corporate human resources managers, a comprehensive and rigorous body of evidence of the educational impacts of ICT interventions in developing cities does not yet exist and is needed to better understand. Program evaluation is an essential component to the implementation of effective educational interventions, especially those that employ innovative technologies. Creating a standardized evaluation framework that is flexible enough to allow for the multitude of resource constraints, as well as other economic and socio-cultural factors often found in developing cities.

\section{DISCUSSION}

\section{A. The 4Is Framework: Introduction, Investigation,} Internationalization, and Implementation

Projects for workers' corporate learning are most often judged in terms of efficiency, effectiveness, and its influence on teaching and learning. Leaving aside the issue of whether or not workers have the capacity to professional development, what would a framework for it look like? What criteria would workers' corporate learning have to meet in order to be considered socially just in a developing country like China? The authors have developed a 4Is framework using criteria of Introduction, Investigation, Internationalization and Implementation as follow: 
TABLE I.

FRAMEWORK FOR CONTINUING PROFESSIONAL DEVELOPMENT IN CORPORATE LEARNING

\begin{tabular}{ll}
\hline The 4 Is & Guidelines for ICT corporate learning \\
\hline - & Introduce the usefulness of ICT appli- \\
cation in their job and related training \\
opportunities available \\
- Continuing education opportunities \\
are provided beyond initial training. \\
- Workers have some freedom of choice \\
introduction what and how they learn. \\
- Information about the availability of \\
learning opportunities and profes- \\
sional development is freely available. \\
- Find out barriers (organisational, geo- \\
graphical, motivational, financial) to \\
workers' use of available learning re- \\
sources and opportunities are re- \\
moved, as far as possible. \\
- Infrastructure is in place to make ac- \\
cess to and engagement with profes- \\
sional development a real possibility, \\
and is sustainable. Policies and moni- \\
toring are in place.
\end{tabular}

Learn best practice from overseas experience such as:

- The provision is equitable and fair.

- Standards of quality are explicit, monitored and maintained.

Internationalization

- The provision is in accord with workers' labour rights (according to International Labour Organisation guidelines)

- The provision responds and adapts to the needs and best interests of workers, collectively and individually.

Implementation

- The provision and system takes account of local variation.

- The learning resources promote core values of the workers' role in fostering social justice.

The quality of workers' continuing corporate learning in developing cities is an issue in many countries. Workers in developing cities tend to be recipients of lower quality in-service training provision than their peers in a more developed city. Where cascade systems of training are the norm, the lower levels of training and resources are often poorer quality than those at the top. As the rapid urbanization process in China, more multi-national companies are setting up their offices in developing cities. Workers' continuing corporate learning is becoming an important issue. Our 4Is framework offers an alternative model, where good quality training opportunities can be distributed more equitably across the system, either through the materials, the technology, or face-to-face sessions with trainers from all levels. There is more interaction between trainers and workers, up and down the different levels of the system as well as with training institutions and peer-trainers.

The previous supply-driven provision for workers' ICT corporate learning shifted towards a demand-initiated one, partly because the variety of learning resources enabled choice and partly because of the way the system was organised. Whereas formerly, priorities and programmes had been determined by the regional headquarter in a well developed city far removed from realities, the "Implementation" component of the suggested framework enables workers and training centres themselves to construct a programme of professional development based on their assessment of their own needs combined with company priorities. It is also possible for individual workers or small groups to work together on their particular interests with the support of ICT resources. This shift raised workers' awareness about their own role of professional development in corporate learning, instead of remaining passive recipients of provision.

Under the suggested framework, many workers are able to create their own materials, in hard copy or in computer formats. These include lesson plans, simple animated courseware, PowerPoint lesson presentations for use in class, reflective writings, collections of downloaded resources, and small research papers. Instead of workers' records at training centre being used purely for administration purposes, they begin to be portfolios of their work and learning. They are begin encouraged to share the resources they create on the company main intranet, and with other workers in the other locations.

The next question is how can ICT be integrated into the corporate learning system. Clearly this requires a systemic approach that is governed by clear policy and implementation processes and plans.

\section{1) Policy Processes for a Systemic Approach}

Any effort to integrate ICT into the corporate learning system requires the leadership of the corporate and the human resources trainers, working together with other outsourced partner if there is any. This leadership must have a clear vision of why the corporate is enabling the use of ICT within the various sectors of the training system and the type of achievement it hopes to achieve by doing so. It also must have a clear vision of the mechanism that the corporate intends to use to implement ICT. This vision then needs to be integrated with company policies.

Why is this needed for policy to inform a systemic approach so vital to the successful integration of ICT into the corporate learning system?

The pervasive nature of technology and its effects (either directly or indirectly) in a company affects how staffs approach and access it. Technology use depends on many factors: access, money, personal interest, perceived value, etc. In the corporate learning system, this uneven application of technology can result in a huge digital and knowledge divide in a company especially at a remote location. Some outsourced training centres have technology literate teachers and/or money and will use ICT, while other centres those poorer and less literate in technology, will be left behind. In the context of corporate learning, having a sound policy, as well as an implementation strategy that complies with that policy, could result in a more systematic introduction to and use of ICT.

Once this vision, policy and implementation strategy for using ICT in the corporate learning system is developed, the next step is ensuring that this policy is integrated into the general training policy. However, some company decision makers prefer to keep the policy of ICT in the training system separate, and instead ensure that it is congruent with other policy statements.

But what constitutes good policy? Needless to say, there is no single policy document or template that can meet the needs of all companies and address all contexts. 
There are, however, generic elements that any policy on ICT in corporate learning should cover. These are:

- a careful analysis of the current context that the city finds itself in with respect to the type of society and economy that is being built and the education system necessary to contribute to it;

- research and analysis of international developments and trends in ICT use in corporate learning; and

- an outline of the key issues that need to be addressed together with proposed methods of doing so.

Based on this analysis and research, a policy for introducing ICTs into the corporate learning system should address the following elements. Preparing all sectors of the education system to understand the investment in and value of technology It is important for any policy to outline the preparatory steps needed to ensure that outsourced training centres and other components of the training system are ready to use the technologies for training purposes.

2) Preparing training centres to accept united technology standard

This includes constructing a policy to enable certain basic infrastructure such as electricity, phone lines, buildings, safe and secure environment and insurance are available to the company required standard. Certain minimum infrastructure requirements are important to enable the use of ICT.

\section{3) Procuring and installing the technology}

Any policy statement needs to address the type of hardware, operating systems and software that would be conducive to learning centre environments in the city, or at least to identify a decision-making framework. This includes models for efficient, affordable, quality access to the Internet for learning centre. Such elements would also need to set student-computer ratio targets and technical support mechanisms.

\section{4) Training teachers to use ICT}

Trainers need to understand the application of ICT to support their teaching and administration. Therefore policy should identify ways of improving trainers capacity in the use of ICT as well as their specific integration into training systems and pedagogical models. The policy should also outline the type of additional staffs required to support computers and related technologies.

\section{5) Developing and managing content}

The value of using ICT in the training centres is best realized when appropriate content is developed and used to enhance and support learning, teaching, administration and management. This involves the production and consumption of local, relevant and appropriate training content through multimedia application of ICT. Therefore, policy in this area is vital to provide for the development and use of content.

\section{6) Planning for continuous evaluation and research}

Policy on research and evaluation is critical within the context of dynamic and changing ICT and its application to the training environment. The constant research and evaluation agenda will ensure that improvements are made to how ICT is used in the training system, and this data and analysis will contribute to any review of policy.

7) Integrating curriculum
ICT on its own has limited uses in the training system. Its intrinsic value lies in the integration of the technology to support and enhance learning and teaching in various subjects. Policy options that identify mechanisms and frameworks that encourage this integration are, therefore, important.

\section{8) Providing ongoing technical support}

The use of ICT in the training system requires different levels of technical support. Policy on using ICT in training needs to identify the levels of technical support necessary and outline how those needs would be addressed. For example, the first line of technical support would need to be based within the school, which requires the training of teachers. Further technical support via help facilities, contracts with local technicians and companies could also be factored into the policy. The macro technical support would be given by the headquarter.

\section{9) Providing ongoing curriculum support}

The ongoing support of trainers is crucial to enable increased and better use of ICT. Such support would include how to integrate the use of ICT when teaching different subjects. Policy in this area will also indicate to the trainers what is expected of them and the type of support they could expect.

\section{0) Developing partnerships}

Implementing ICT in the corporate learning requires a substantial amount of money and skilled personnel. Therefore partnerships between companies and the outsourced training centres and others become important. The identification of this approach is important to include in any policy document.

The way a outsourced system is structured also has an impact on ICT in training policy. The level of centralization or decentralization of a company's training system will determine how policies are constructed, the nature of what is being proposed and how it will be implemented. It will also determine how "top-down" or "grass roots" the policy and implementation will be. In many developing cities, using a decentralized approach could result in a lack of central co-ordination, implementation and funding. Such uneven development and implementation of the policy could result in new divides emerging in the training system. Therefore policy development is needed at a central level to provide a sound framework for ICT, while allowing for and enabling local community level involvement.

\section{CONCLUSION}

The use of distance education and ICT has the potential to distribute opportunities for corporate learning more widely and equitably. It can also improve the quality and variety of the resources and support available to workers, opening up new avenues to professional development. If social justice is to be achieved however, in terms of equity of educational opportunity and services, the provision needs to be planned in ways that make it empowering them to make choices in what and how they learn. It also needs enabling policies in support of these aims.

The suggested framework is useful for developing cities in making opportunities available for workers' professional development on a large scale. Taking a schoolbased approach supported by ICT, it provides more inclusive access than the previous arrangements while at the 


\section{PERSONAL DEVELOPMENT EMPOWERMENT THROUGH ICT IN CORPORATE LEARNING: A Case Study of Two Developing Cities in China}

same time extending learning opportunities beyond the boundaries of the learning centre. It shifts the emphasis from a supply-driven provision to a demand-initiated one, giving workers and trainers more ownership and choice in their professional development. The shift is only possible through taking a system-wide approach to workers in developing cities rather than just setting up ICT centres disconnected from the mainstream management of workers' continuing training and having little impact on it. According to our in-depth interview, the suggested framework is popular and acceptable to workers and trainers because it meets their needs and offered something new. It is also adaptable, accommodating different kinds of learning and training activities, acting as an open learning centre, varying its provision and scope according to local context while retaining a common core mission and set of activities.

Though the use of ICT have the capacity for large-scale delivery over huge distances, the main benefit comes from what happened beyond delivery, namely, the mobilisation of workers, the generation of activities at the local level, and the changes in knowledge, skills, attitudes, and mindset of workers and trainers. While the technology opens the way to new possibilities, the factors that contribute to its successful use are strong commitment from leaders at various levels, enabling policies, an emphasis on human resource development rather than equipment, the organisational structure of a corporate, good quality learning resources, workers' keen motivation to learn and rewards for their participation, effective monitoring practices, and sufficient funds to carry out the activities needed.

\section{REFERENCES}

[1] International Labour Organization [ILO]: World Employment Report 1998-99, [Geneva: International Labour Office], 1998.

[2] M Tomlinson,.: "The learning economy and embodied knowledge flows”, University of Manchester: Centre for Research on Innovation and Competition, CRIC Discussion Paper 26, 1999.

[3] A.S Bhalla.: Facing the Technological Challenge, [London: Macmillan for the International Labour Organization], 1996.

[4] D Light., F Method., C Rockman., , G.M Cressman., \&, J Daly.. Synthesis report: Overview and recommendations to the Jordan Education Initiative. Washington, DC: Education Development Center, Inc. 2008
[5] L.L Linden,. Complement or substitute? The effect of technology on student achievement in India. Infodev Working Paper No. 17. 2008 Available: http://www.infodev.org/en/Publication.505.html

[6] J Angrist,. \& V Lavy, New evidence on classroom computers and pupil learning. The Economic Journal, 112, 735 - 3652002. doi:10.1111/1468-0297.00068

[7] J.E Hinostroza., A. Guzmán, \& S. Isaacs.. Innovative uses of ICT in Chilean schools. Journal of Computer Assisted Learning. 18(4), 459-469. 2002. doi:10.1046/j.0266-4909.2002.00257.doc.X

[8] P Hepp., E Hinostroza., E Laval. \&, L Rehbein.. Technology in schools: Education, ICT and the knowledge society. Washington: The World Bank. 2004

[9] M Bakia. The costs of computers in classrooms: Data from developing countries. Washington, DC 2001: The Consortium for School Networking. Available: http://classroomtco.cosn.org/ cic.pdf

[10] M Potashnik. and A Douglas. Cost Analysis of Information Technology Projects in Education: Experiences from Developing Countries. Education and Technology Series, 1(3). Washington, DC: The World Bank. 1996

[11] L Wolff.. Costa Rica: Are computers in school effective? TechKnowLogia 1999. Available: http://www.techknowlogia.com/ TKL active pages2/CurrentArticles/main.asp?IssueNumber $=2$ \&FileType $=$ PDF\&ArticleID $=42$

[12] Commonwealth of Learning.. An international scan of the use of ICT in education. Washington, DC: Commonwealth of Learning. (year unknown)

[13] R Kozma, R McGhee , E Quellmalz. \&, D Zalles.. Closing the digital divide: Evaluation of the World Links Program. International Journal of Educational Development, 24(4), 361-381 2004. doi:10.1016/j.ijedudev.2003.11.014

[14] D Light. \&, M Manson . An educational revolution to support change in the classroom: Colombia and the educational challenges of the twenty-first century. Washington, DC: Education Development Center, Inc, Center for Children and Technology 2007.

[15] M Powell. Rethinking education management information systems: Lessons from and options for less-developed countries 2006. Infodev Working Paper No. 6. http://www.infodev.org/ en/Publication.504.html

\section{AuTHORS}

S. Lam was with New College, Oxford University. He is now with the Social Sciences Division, Oxford University, UK (e-mail: sancheslam@gmail.com).

Ho Kin Fai is a post-doc fellow with Hong Kong Polytechnic University, Hong Kong. (852) 21626410.

Manuscript received March 20, 2010. Published as resubmitted by the authors May 22 $2^{\text {nd }}, 2010$. 